\title{
DIGITAL MODELLING AND SIMULATION IN FRENCH SOCIAL SCIENCES AND HUMANITIES RESEARCH: AN EXPLORATORY STUDY
}

\author{
Nathalie Pinède \\ Bordeaux Montaigne University \\ MICA \\ 33607 Pessac cedex, France \\ nathalie.pinede@u-bordeaux-montaigne.fr \\ Saikou Y. Diallo \\ Virginia Modeling, Analysis \& Simulation Center \\ 1030 University Blvd \\ Suffolk, VA 23435, USA \\ SDiallo@odu.edu
}

\author{
Bruno Vallespir \\ Mamadou K. Traoré \\ Univ. Bordeaux, CNRS, \\ IMS, UMR 5218 \\ 33405 Talence, France \\ bruno.vallespir@ims-bordeaux.fr \\ mamadou-kaba.traore@ims-bordeaux.fr
}

Grégory Zacharewicz

LG2IP - IMT École des Mines d'Alès

6 avenue de Clavières

30319 Alès Cedex

Gregory.Zacharewicz@mines-ales.fr

\begin{abstract}
This text proposes an exploratory study to try to identify the place of modelling and simulation-oriented approaches in the social sciences and humanities (SSH). In particular, we will focus on French research in this field. We chose to use the Google Scholar search tool to conduct our investigations. We will present our methodological approach and the main results that can be proposed at this stage.
\end{abstract}

Keywords: digital, social sciences and humanities, modelling and simulation, exploratory study.

\section{INTRODUCTION}

The development of digital models and simulation is no longer limited to the design and evaluation of technical objects but is now available in all fields of research, engineering and management. The modelling and analysis of territorial development or social behaviour take advantage of these new possibilities. In particular, the increase in computing capacity makes possible the analysis of systems composed of a very large number of autonomous, heterogeneous and weakly coupled actors. Within the framework of a research project aimed to structure an interdisciplinary community around the themes of modelling and digital simulation, the objective of this work is to present a state of the art of French research in Social Sciences and Humanities (SSH) on this subject. More precisely, the aim is to get a first response, with an exploratory study, to the following questions: What are the contributions of these methods, compared to other methods traditionally used in SSH (qualitative methods - interviews, observation... or quantitative questionnaires, etc.)? What are the main disciplines involved in these approaches? What are the challenges while digitalization of society and human activities is continuously increasing? Finally, what are the main human and societal issues in SSH managed with these methods and analysis tools? 
After having defined what we mean here by digital modelling and simulation, we will propose a French mapping of disciplines, themes and models, based on an analysis of scientific production over the last 10 years (using Google Scholar). We will supplement this macroscopic point of view with a focus on the "territories and societies" issues, from which we will present different types of use of modelling and simulation approaches. Finally, we will conclude on the interest of these first results but also on the need of further explorations on the role of these topics and methods of research for the Social Sciences and Humanities.

\section{SSH IN FRANCE: SCOPE AND METHODS}

\subsection{Scope of SSH in France}

Defining the perimeter of the Social Sciences and Humanities (SSH) in general and in France in particular is not so simple. In France, in particular, this is made difficult by a complex institutional situation marked by a tangle of structures and organizations (Maurel 2016). Thus, until 2010, four different nomenclatures coexisted to qualify SSHs, from different national bodies involved in one way or another in the structuring or evaluation of academic research in France. Often dated, heterogeneous, and possibly marked by disciplinary compartmentalization leading to forms of fragmentation, they are detrimental to the readability of SSH research. For example, the National Committee for Scientific Research has identified 10 sections relating to SSH research issues since 1970; the National Council of Universities has identified 31 sections for SSH; and the Agency for the Evaluation of Research and Higher Education has identified 7 SSH panels.

In 2010, the National Strategy for Research and Innovation (SNRI), under the aegis of the French Ministry of Higher Education and Research, proposed a new reference system, based on the four nomenclatures mentioned above, on an updated approach to the SSH domain, and on the taxonomy proposed by the European Research Council (ERC) around 6 panels (SNRI 2010).

The new nomenclature is therefore divided into 6 main groups (Table 1).

These 6 groups thus offer a comparison of disciplines on the basis of the major fields of study identified, disciplines which nevertheless emerge through the keywords proposed to define the groups. Despite this effort to synthesize and this desire for clarity, the disciplinary approach continues to structure the research in France, particularly for the careers of teachers-researchers.

In the analyses that we will subsequently propose, we will try to take into account both this grouping by field (groups) and the disciplinary approaches that make it up (keywords).

\subsection{Methods in SSH}

The SSH field thus remains marked by a great diversity of disciplinary viewpoints, and therefore, of objects of study and scientific practices. As such, it mobilizes methods of access to reality, collection techniques and data analysis methods that are extremely varied within the field itself. In his panorama of data collection and analysis techniques in SSH, L. Morillon (2008) makes a classic distinction between qualitative approaches (favouring micro investigations and the richness and variety of data - for example, studies of discursive traces, interviews, observations) and quantitative approaches (description by measuring a situation on a sufficient scale - for example, questionnaires, surveys or approaches oriented towards digital humanities). This distinction, which has an undeniably operative side, is not always as strict as that, however. Mixed methods research makes it possible to go beyond the opposition between qualitative and quantitative methods, in order to benefit from the advantages of both, thus constituting a third research paradigm (Johnson and Onwuegbuzie 2004). "Mixed methods research [...] uses quantitative and qualitative research methods, either concurrently (i.e., independent of each other) or sequentially (e.g., findings from one approach inform the other), to understand a phenomenon of interest" (Venkatesh et al. 2013, p. 23). On the other hand, D. Courbet (2011) specifies that to these two major families of data collection (qualitative 
and quantitative methods), we must add experimental methods (i.e., the creation of a controlled experiment situation using a protocol that includes different techniques).

Table 1: New SNRI nomenclature (SNRI 2010).

\begin{tabular}{|c|c|c|c|}
\hline Groups (French) & Groups (English) & Keywords (French) & Keywords (English) \\
\hline $\begin{array}{l}\text { SSH1-Marchés et } \\
\text { organisations }\end{array}$ & $\begin{array}{l}\text { Markets and } \\
\text { organizations }\end{array}$ & $\begin{array}{l}\text { Économie, finance, } \\
\text { management }\end{array}$ & $\begin{array}{l}\text { Economics, finance, } \\
\text { management }\end{array}$ \\
\hline $\begin{array}{l}\text { SSH2-Normes, } \\
\text { institutions et } \\
\text { comportements } \\
\text { sociaux }\end{array}$ & $\begin{array}{l}\text { Norms, institutions } \\
\text { and social } \\
\text { behaviour }\end{array}$ & $\begin{array}{l}\text { Droit, science politique, } \\
\text { sociologie, } \\
\text { anthropologie, } \\
\text { ethnologie, démographie, } \\
\text { information et } \\
\text { communication }\end{array}$ & $\begin{array}{l}\text { Law, political science, } \\
\text { sociology, anthropology, } \\
\text { ethnology, demographics, } \\
\text { information \& } \\
\text { communication }\end{array}$ \\
\hline $\begin{array}{l}\text { SSH3-Espace, } \\
\text { environnement et } \\
\text { sociétés }\end{array}$ & $\begin{array}{l}\text { Space, environment } \\
\text { and societies }\end{array}$ & $\begin{array}{l}\text { Etudes } \\
\text { environnementales, } \\
\text { géographie physique, } \\
\text { géographie sociale, } \\
\text { géographie urbaine et } \\
\text { régionale, aménagement } \\
\text { du territoire }\end{array}$ & $\begin{array}{l}\text { Environmental studies, } \\
\text { physical geography, } \\
\text { social geography, urban } \\
\text { \& regional geography, } \\
\text { land use planning }\end{array}$ \\
\hline $\begin{array}{l}\text { SSH4-Esprit } \\
\text { humain, langage, } \\
\text { éducation }\end{array}$ & $\begin{array}{l}\text { Human mind, } \\
\text { language and } \\
\text { education }\end{array}$ & $\begin{array}{l}\text { Sciences cognitives, } \\
\text { sciences du langage, } \\
\text { psychologie, sciences de } \\
\text { l'éducation, Sciences et } \\
\text { techniques des activités } \\
\text { physiques et sportives }\end{array}$ & $\begin{array}{l}\text { Cognitive sciences, } \\
\text { language sciences, } \\
\text { psychology, educational } \\
\text { sciences, physical } \\
\text { activity \& sports science }\end{array}$ \\
\hline $\begin{array}{l}\text { SSH5-Langues, } \\
\text { textes, arts et } \\
\text { cultures }\end{array}$ & $\begin{array}{l}\text { Languages, texts, } \\
\text { arts and cultures }\end{array}$ & $\begin{array}{l}\text { Langues, littérature, arts, } \\
\text { philosophie, religion, } \\
\text { histoire des idées }\end{array}$ & $\begin{array}{l}\text { Languages, literature, } \\
\text { arts, philosophy, religion, } \\
\text { history of ideas }\end{array}$ \\
\hline $\begin{array}{l}\text { SSH6-Mondes } \\
\text { anciens et } \\
\text { contemporains }\end{array}$ & $\begin{array}{l}\text { Ancient and } \\
\text { contemporary } \\
\text { worlds }\end{array}$ & $\begin{array}{l}\text { Préhistoire, archéologie, } \\
\text { histoire, histoire de l'art }\end{array}$ & $\begin{array}{l}\text { Prehistory, archaeology, } \\
\text { history, art history }\end{array}$ \\
\hline
\end{tabular}

Within the groups identified in the SNRI nomenclature, the positions (positivist, constructivist, understanding or functionalist) as well as the associated scientific approaches vary greatly from one discipline to another. Indeed, while some disciplines may be close to the so-called exact sciences in their approaches (i.e. archaeology, physical activity \& sports science, cognitive sciences, economics...), most remain very attached to qualitative investigative approaches (observation, interviews, critical analysis of textual corpuses, etc.). In particular, model-based approaches and the use of simulation seem to be in the minority in the SSH field in general. Thus, in J-M. Berthelot's book on the epistemology of social sciences (2012) and in the index of concepts, "simulation" only refers to the chapter devoted to economics. It is questionable whether the current trend of digitally mapping the observable world (present and past) is not an interesting opportunity for SSH.

Before asking the question of opportunities, we propose here to present the results of an exploratory study on the use of modelling and digital simulation in SSHs as we have previously defined them. 


\section{EXPLORATORY STUDY}

Note to the reader: Throughout the rest of this paper, keywords are indicated in English. It is in fact only the translation of the French keywords that were actually used for our research, according to the French use of these terms to represent disciplines and domains.

In this study, we first propose a macroscopic view of modelling and digital simulation approaches in French-speaking SSHs. In a second step, we will focus on the theme "territories and societies", in order to leave a reading mainly oriented by disciplinary fields to observe how, on a favourable theme to the mobilization of simulation-type approaches, SSHs position themselves. This theme "territories and societies" was chosen because it corresponds to research work that has already been undertaken at the University of Bordeaux or the VMACS laboratory (see §2.3).

\subsection{Methods}

We opted for an exploratory approach based on the Google Scholar search tool, exploring the Frenchspeaking academic field ("pages in French"). The main keywords selected for our research were the following, written in this order: "model digital simulation". We made a first exploration on these keywords, in order to see what, "spontaneously", emerged. To these main keywords, we then added different keywords to refine our queries around the SSH domain.

First of all, we made a first macroscopic approach from the keywords "humanities", "social science" and "social science and humanities". Secondly, in order to continue our macroscopic approach of the SSH domain while specifying the concerned themes, we systematically added the keywords presented in table 1 to characterize the different groups of SSH. This results in queries such as "law model digital simulation", "political science model digital simulation", "sports physical activities" (for STAPS), etc. That is to say 30 queries in total. Finally, in order to focus on the theme "territories and societies", the keywords "territory", "society" and "territory society" have been cross-referenced with the main keywords ("digital simulation model").

As far as the results are concerned, we have chosen to retain only the results corresponding to the ten last years, by selecting the search by date from 2010. Furthermore, we have limited our selection to the first 50 results, excluding patent results but keeping the citations. Finally, for the processing of our results, we have only kept the title, author and date, reserving the possibility of consulting the source if further verifications were necessary.

Of course, this approach has many limitations, which we will see in particular from the analyses carried out. The choice of a tool such as Google Scholar, relatively generalist and opaque on the methods of classification of the proposed results (variable classification according to the time, moreover), does not allow a great precision of analysis. Nevertheless, as we are trying here to give a global overview, the Google Scholar tool has real advantages.

\subsection{SSH, models and digital simulation: a macroscopic perspective}

A first exploratory approach on the keywords "model", "simulation" and "digital", without specifying a domain, reveals the near absence of SSH in the first 50 results. Only one author, F. Varenne whom we can associate with the SSH domain and whom we will see coming back often afterwards, appears three times in the results, including one particularly related to SSH (Varenne, 2010). It should be noted, however, that on two occasions studies were more related to a problem oriented towards "territories and societies" and from an engineering perspective: flood risks and atmospheric pollution.

\subsubsection{Generic SSH domain approach}

In the first instance, we have focused on the intersection with the keywords "humanities", "social science" and "social science and humanities". Out of the 150 results obtained with these queries, 82 were retained, 
once the results deemed off-topic (11) and the results appearing two or even three times (i.e. 57 results) were eliminated. Of these 82 results, a few observations can be made. First of all, the presence of a recurring author, F. Varenne, with 9 distinct occurrences out of these 82 results (11\% of the results). If we look only at the titles of the texts, the keywords "model", "simulation", "digital" have the presence rate indicated in Table 2 .

Table 2: Rate of presence of keywords in titles for generic SSH approach.

\begin{tabular}{|l|l|l|}
\hline Simul & 30 & $36,6 \%$ \\
\hline Model & 33 & $40,2 \%$ \\
\hline Numer & 27 & $32,9 \%$ \\
\hline
\end{tabular}
To allow for a broader search, the search was done using the above truncations ("numer" is for digital)

It should also be noted that most of these terms appear independently: for example, 16 titles (19.5\%) speak of both model (or modelling) and simulation, while only 6 titles (7.3\%) speak of both simulation and digital modelling. We can see that the cross-references between keywords are not systematic, far from it.

Several rankings were also made on these 82 results. An exploration of the authors' side reveals some interesting elements (Table 3).

Table 3: Distribution of authors by SSH affiliation.

\begin{tabular}{|l|l|l|}
\hline SSH Authors & non SSH Authors & SSH and non SSH Authors \\
\hline $60(73,2 \%)$ & $11(13,4 \%)$ & $11(13,4 \%)$ \\
\hline
\end{tabular}

While the vast majority of the authors come from an SSH domain, it is interesting to see also that non-SSH authors appear in these results because they are interested in issues of modeling and digital simulation for $\mathrm{SSH}$, both epistemologically and application-wise. Finally, we note the presence of $\mathrm{SSH} / \mathrm{non}-\mathrm{SSH}$ collaboration, which is in line with the interdisciplinarity often advocated in relation to these approaches.

On the other hand, a distinction has been made between work that uses modelling and simulation tools ("Application") and work that proposes a critical perspective ("Epistemology") in relation to these objects (digital, models, simulation). From this distinction, we obtain the following distribution: a majority of the results $(50$, i.e. $61 \%$ of the whole) have rather an epistemology-oriented vision related to the stakes of simulation, digital and modelling; 32 results (i.e. 39\%) are rather oriented towards application, with a more or less strong recourse to modelling and digital simulation tools (only 9 results $-28 \%$ - show a multi-agent approach).

If we refine the results within these two main categories slightly, we also see significant differences in positioning on the basis of the dominant theme or main field (Figures 1 and 2). The themes that appear in these figures are those that emerge most often in our research.

In the Epistemology-oriented results, it is generalist ("SSH") works that clearly emerge (36\%). Then a subject of interest related to the Digital Humanities (8\%) and a field, sociology (also 8\%) appear. In the Application results, on the contrary, it is a field, geography, which is largely dominant (31\%), followed by work related to architecture (12.5\%). Logically enough, the generalist results related to SSH are much less present in this section (12.5\%). The presence of approaches related to disciplines (13 in number) is very marked in this Application section. In the Epistemology rubric, in addition to the presence of these disciplinary approaches (12 in number), there are also cross-cutting questions related to the objects of study around simulation, models and digital technology: digital humanities, methods, interdisciplinarity or video 
games. Finally, it should be noted that certain disciplinary approaches are common to both types of work while others are specific to one or the other (Table 4).

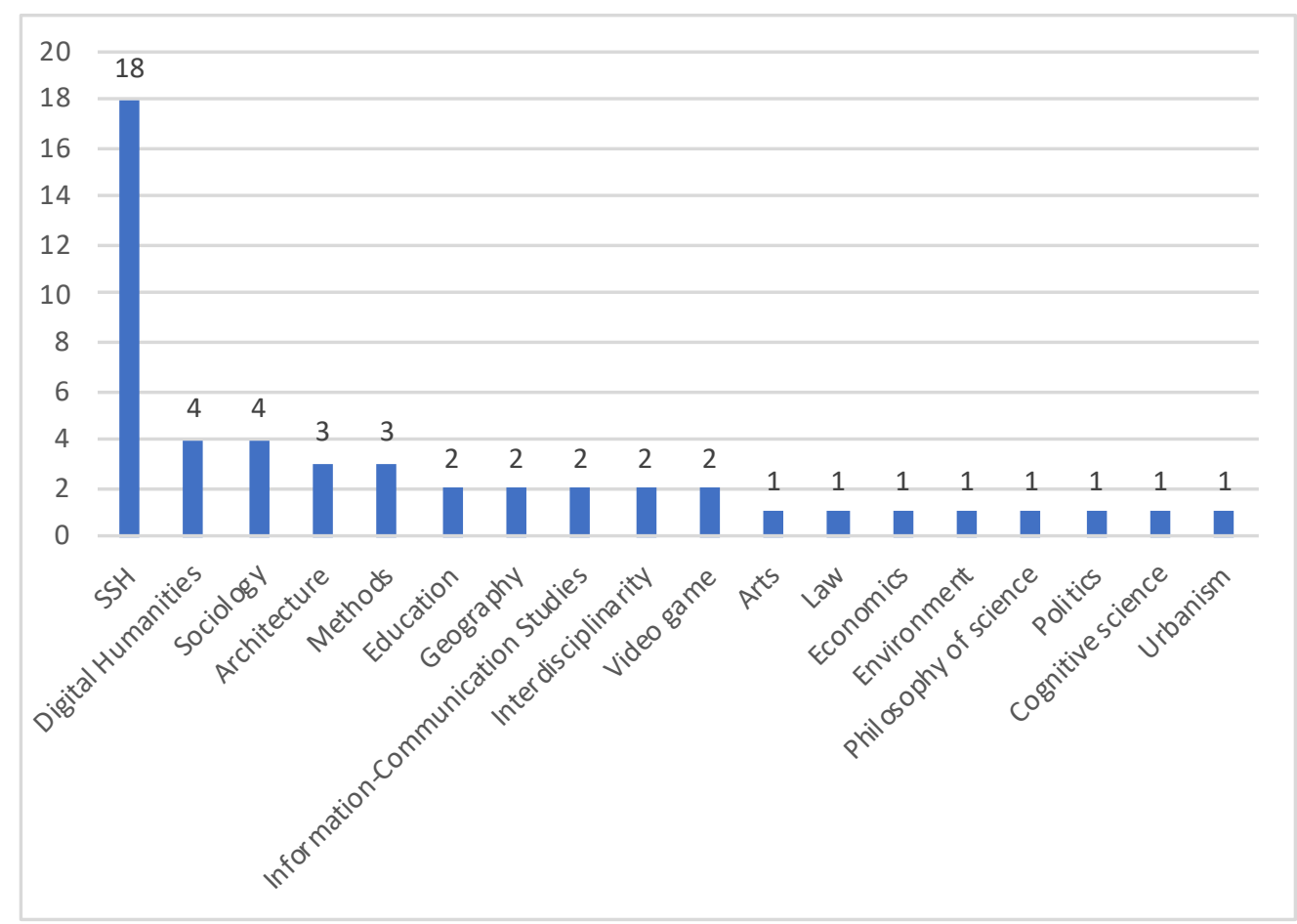

Figure 1: Epistemology - Main topics and fields.

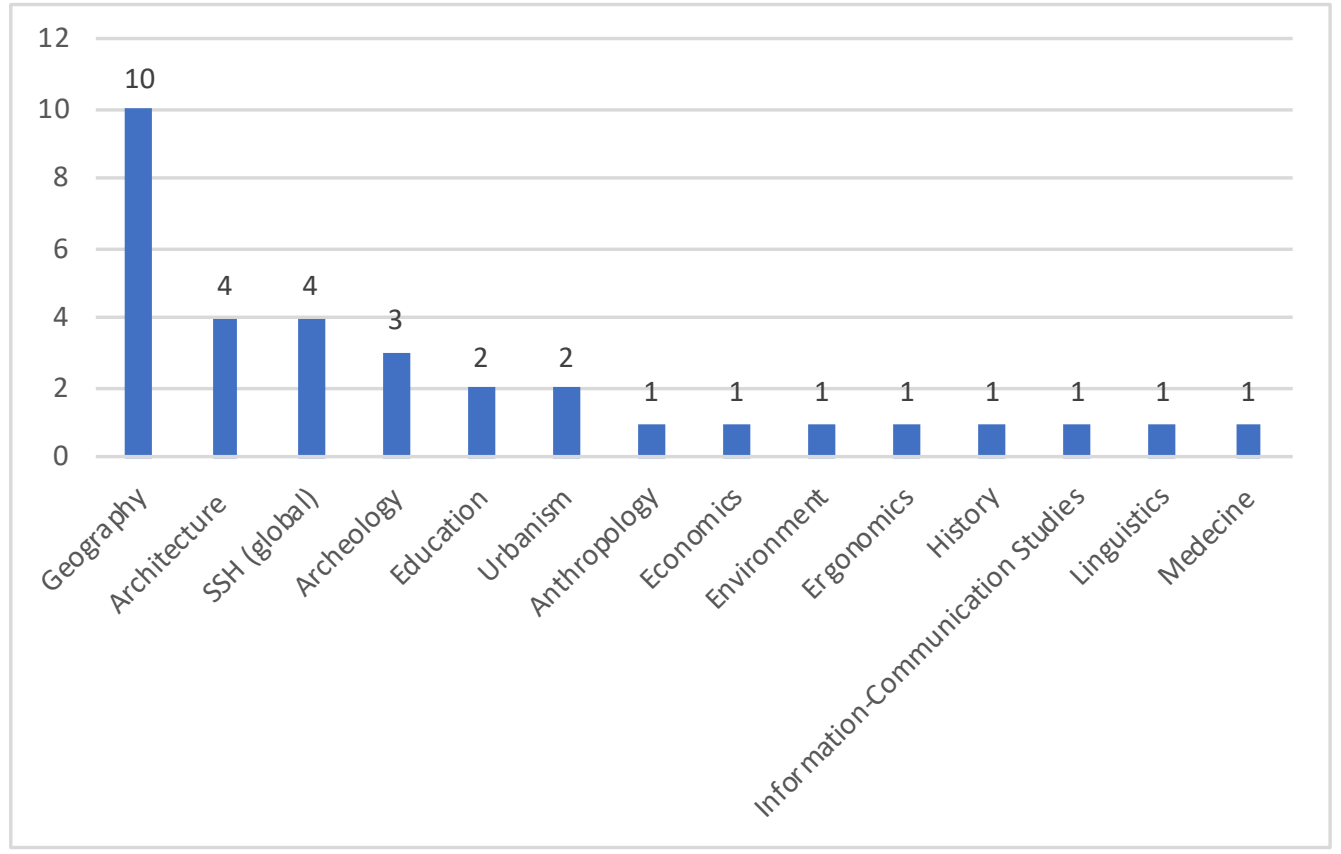

Figure 2: Application - Main topics and fields.

Of course, given the small number of results, they are not representative but purely illustrative. Nevertheless, they may reveal trends, which we will see with the second investigation carried out. 
Table 4: Distribution of domains.

\begin{tabular}{|l|l|}
\hline $\begin{array}{l}\text { Common domains ("Epistemology" } \\
\text { and "Application") }\end{array}$ & $\begin{array}{l}\text { Sociology, Architecture, Education, Geography, Information } \\
\text { and Communication Studies, Economics, Environment, } \\
\text { Urbanism. }\end{array}$ \\
\hline Specific domains "Epistemology" & $\begin{array}{l}\text { Arts, Law, Philosophy of Science, Politics, Cognitive } \\
\text { Science }\end{array}$ \\
\hline Specific domains "Application" & $\begin{array}{l}\text { Archeology, Anthropology, Ergonomics, History, } \\
\text { Linguistics, Medecine. }\end{array}$ \\
\hline
\end{tabular}

\subsubsection{Detailed keyword approach to the SSH Domain}

A more detailed analysis in terms of domains was conducted on the basis of the 30 keywords presented in Table 1. For each domain/keyword, a search within Google Scholar was systematically made with the same parameters than before: year from 2010 to today, order of relevance, French language and query in the following form: keyword "modele simulation numerique" (i.e. "model digital simulation"). The first 50 results were kept and analysed.

The analysis remained summary (based on the title) and consisted in classifying the results into three classes:

- Yes: when the reference is related to $M \& S$ and the domain,

- Maybe: when the title might suggest that the development of the reference might evoke our subject of study

- No: when the reference is out of range.

Most of the time, the references have been eliminated (No class) because they obviously refer to another field.

Several biases are evident. First, an analysis based on the title is necessarily summary. Secondly, the domains proposed can lead to extremely polluted searches. This is particularly the case for terms that are heavily used in everyday language such as philosophy, art or even economics. Nevertheless, the fact that the search is based on a criterion of relevance makes it possible to consider that these results are of interest: if irrelevant results appear in the majority, it is because the query itself is irrelevant.

Figure 3 shows the number of "Yes" and "Maybe" for each domain (out of 50). These are ranked from those with the most Yes's and the most Maybes as the second criterion. The first domains have a non-negligible number of references that reflect a certain maturity in terms of M\&S. Conversely, others seem totally impervious to this type of approach. Finally, some domains present a lot of "Maybes", which reflects a strong interest for further analysis of the domain concerned.

A final point to be considered is the nature of the relationship between the domain and M\&S. The two types of relationships (Application or Epistemology) defined in Chapter 2.2.1 can be found here as well. For the first type, the domain is an application domain, i.e. $M \& S$ is an investigative tool. A typical domain in this case is Land-use planning. For second type of relationship, M\&S is considered as a research topic. For example, Philosophy will be interested in the epistemology of digital models or Educational sciences will 
be interested in $M \& S$ as a pedagogical tool. It should be interesting to see if some domains position themselves simultaneously in both cases, that would lead to two quite distinct classes of domains.

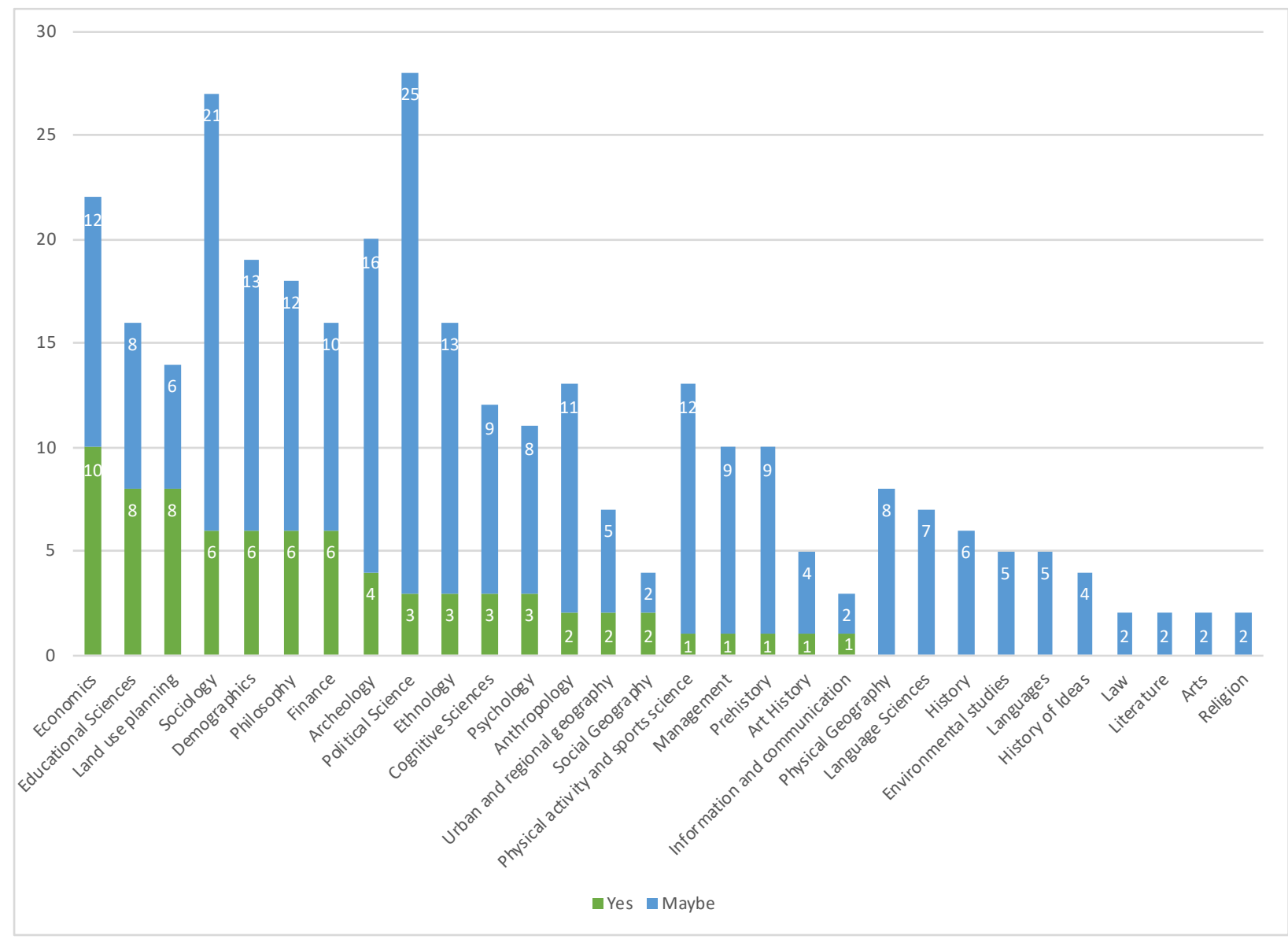

Figure 3: Result of the Google Scholar search of the references associating the 30 domains (table 1) and $\mathrm{M} \& \mathrm{~S}$.

\subsection{Focus on the "Territories and societies" theme}

We will focus on the "Territories and societies" theme that has been chosen for the development of a research project "M\&S and SSH" at the Universities of Bordeaux.

\subsubsection{Motivations}

There are two reasons for this choice.

Firstly, this theme is considered as a privileged meeting place between hard sciences and SSH. Also, it can be a facilitator to implement a willingness of transdisciplinary.

Secondly, results existing prior to the launch of projects in various fields on the Bordeaux academic site could be fairly easily federated under the theme "Territories and Societies". It is within this framework that a seminar entitled "Modelling and simulation for societies and territories" was organised in April 2018 by the MSHA (Maison des Sciences de l'Homme d'Aquitaine -i.e. Aquitaine House of Humanities-) and the IMS laboratory. This seminar can be considered as the founding act of the research project. During this seminar, the following presentations were made: 
- Human simulation by S. Y. Diallo (Old Dominion university) (reference corresponding to this research work: (Diallo et al. 2019)).

- Modélisation et simulation de la propagation d'information dans les réseaux sociaux (Modelling and simulation of information propagation in social networks) by Y. Bouanan, G. Zacharewicz and B. Vallespir - IMS (references corresponding to this research work: (Bouanan et al. 2016a), (Bouanan et al. 2016b)).

- Modélisation et simulation appliquées au domaine de la santé : Etude d'un territoire de santé rural (Modelling and simulation applied to the healthcare field: Study of a rural health territory) by M. Sbayou, G. Zacharewicz and B. Vallespir - IMS (references corresponding to this research work: (Sbayou 2019), (Zeigler et al. 2019 pp. 215-250)).

- MUST-B : un modèle de simulation basé agent pour l'aménagement des territoires urbains (MUST-B: an agent-based simulation model for urban land use planning) by S. Zerguini, Y. Bouanan and N. Gaussier - Gretha (laboratory of economics) (references corresponding to this research work: (Bouanan et al. 2017), (Zerguini et al. 2017)).

The content of this seminar perfectly illustrates the themes on which simulation specialists from hard sciences can work on subjects that are naturally SSH-related.

\subsubsection{Analysis}

The "Territories and societies" theme was addressed through the "territory", "society" and "territory society" keywords. The results produced by these different requests are very diversified and finally leave little room for SSH productions: only 38 results out of the 150 obtained were identified as coming from $\mathrm{SSH}$, i.e. barely a quarter of all results. This is obviously not much and shows the limits of an approach using keywords as open as "territory" or "society". It should be noted that in the results that were not retained for further exploration, while the majority are related to issues in the exact or applied sciences (materials, acoustics, hydrology, climate, solar and wind energy, mathematics and statistics), others, although dealt with from a non-SSH point of view, are related to human or societal issues. This concerns, for example, risks related to floods, the environment, agriculture or urban mobility and transport.

The occurrences of the terms "simulation", "modelling" and "digital" (with their lexical variants) in the titles of the results selected for the study are fairly balanced (Table 5). Nevertheless, they are generally present independently: only 1 title displays the three themes simultaneously, 5 titles talk about " digital simulation" and 2 combine modelling and digital modelling.

Out of the 38 selected results, 27 authors are identified as coming from SSH (i.e. 71\%), 10 authors coauthor papers in an SSH-non-SSH collaboration (26\%) and only 1 is non-SSH. If we compare with the results in table 3, SSH-no SSH collaborations are twice as numerous on the theme "Territories and societies" (26\% versus $13.4 \%)$.

Table 5: Rate of presence of keywords in titles for "Territories and Societies".

\begin{tabular}{|l|l|l|}
\hline Simul & 14 & $36,8 \%$ \\
\hline Model & 12 & $31,6 \%$ \\
\hline Numer & 13 & $34,2 \%$ \\
\hline
\end{tabular}

NB: To allow a broader search, we use the above truncations ("numer" is for "digital")

If we make a distinction similar to the one made in 2.2.1, we obtain a breakdown between "Application" and "Epistemology" according to the following figures: 25 results (i.e. 66\%) fall into the "Application" 
category and 13 (i.e. 34\%) into the "Epistemology" category. This is an inverse proportion to that noted in 2.2.1 where only $39 \%$ of the results corresponded to an application dimension. In addition, and in a similar way to what we have done previously, we have made a distinction within each of these major categories (Figures 4 and 5).

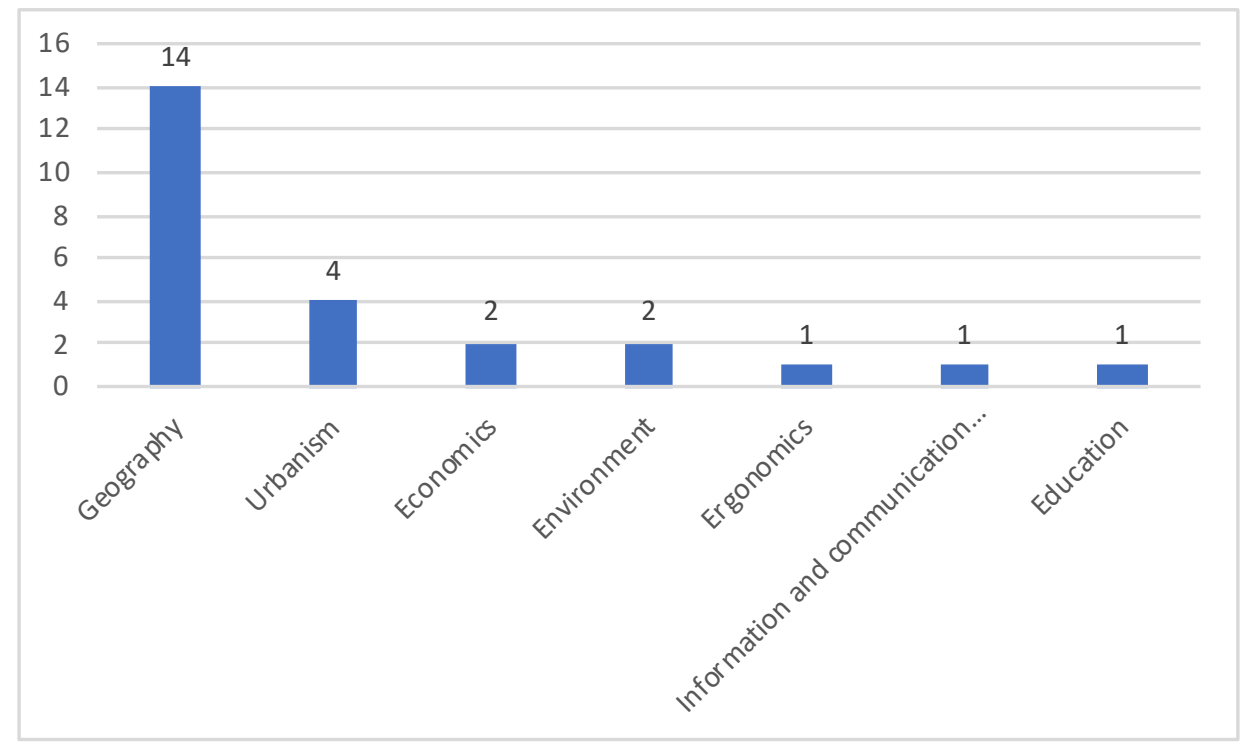

Figure 4: Application - Main topics and fields for "Territories and Societies".

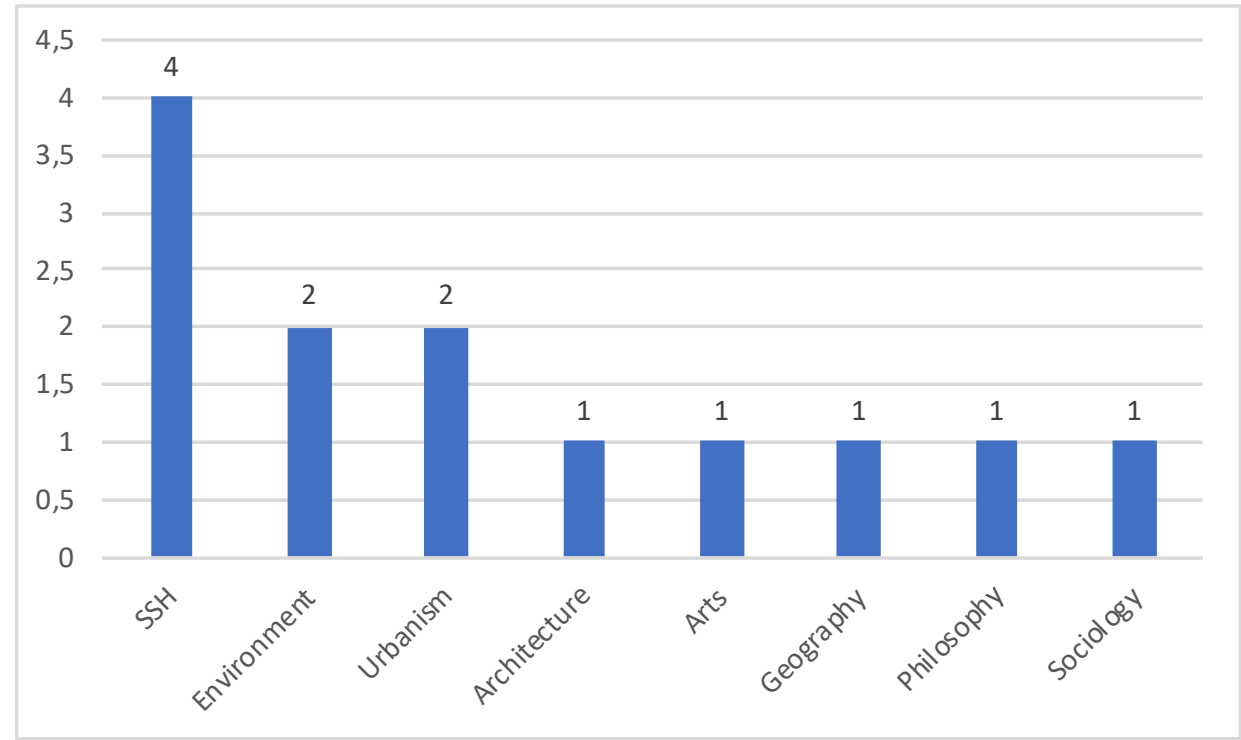

Figure 5: Epistemology - Main topics and fields for "Territories and Societies".

Unsurprisingly, on a theme such as "Territories and societies", geography emerges as the dominant application (56\%), followed by urbanism (16\%). The 5 other approaches (economics, environment, ergonomics, information and communication studies, education) appear much more marginal. With regard to the results of epistemological orientation, while generalist work on SSHs predominates, this is nevertheless relatively evenly distributed among the 7 other approaches. 


\section{CONCLUSION}

The various searches carried out from Google Scholar have obvious limitations, particularly concerning the operationality of certain keywords. The results presented here are only a first study, in order to clear the field. The aim is to launch in a second time a much more precise study using a more rigorous approach based on these initial results. Another interesting point to integrate would be to move away from a purely static analysis to take the evolution over time into account and to identify trends. In order to make this analysis possible, the sample will have to be much broader.

Nevertheless, several points of convergence emerge. Certain disciplines appear to be little concerned by M\&S-oriented approaches (i.e. law, arts, literature). Moreover, there are different degrees of maturity according to the disciplines involved. Some (such as geography, economics, urban planning or architecture) have proven experience with M\&S tools. In other disciplines, it is more of an object of reflection, from an epistemological perspective often included in broader issues, such as those related to digital humanities or interdisciplinarity. One of the main results of this exploratory study therefore concerns the existence of this dual relationship to $M \& S$ approaches, as an investigative tool or a research topic (Figure 6).

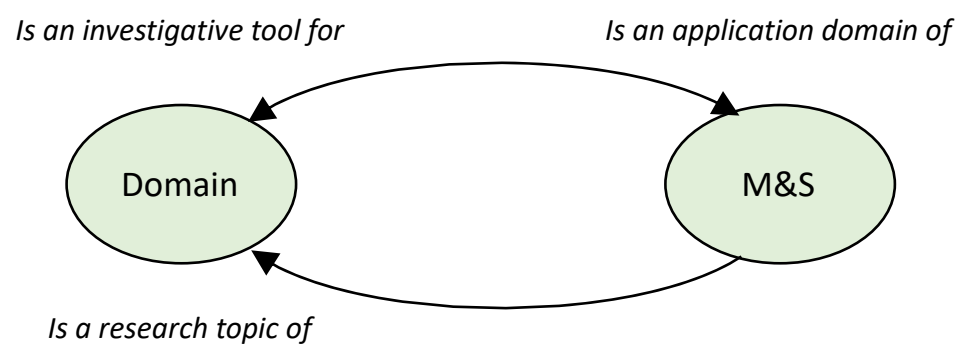

Figure 6: The two types of relationships between the SSH domains and M\&S.

Despite the limitations already highlighted above, this exploratory research has the merit of proposing innovative bases for reflection on the presence of $M \& S$ approaches in the multiple disciplines and scientific cultures that make up SSH. In particular, the difference that emerges between applicative and epistemological viewpoints deserves to be explored in greater depth. With regard to the focus on "Territories and Societies", a majority of applicative approaches in the field of SSH emerge. However, all these trends need to be confirmed by new research, targeting certain subjects or disciplines more precisely.

\section{REFERENCES}

Berthelot, J. 2012. Épistémologie des sciences sociales. Paris, Presses Universitaires de France.

Bouanan, Y., Zacharewicz, G., Vallespir, B., Ribault, J., and Diallo, S. Y. 2016. "DEVS based Network: Modeling and Simulation of Propagation Processes in a Multi-Layers Network". Spring Simulation Multi-Conference (SpringSim), April 3-6, Pasadena, CA, USA.

Bouanan, Y., Zacharewicz, G., and Vallespir, B. 2016. "DEVS modelling and simulation of human social interaction and influence". Engineering Applications of Artificial Intelligence, Elsevier, vol. 50, pp. 8392.

Bouanan, Y., Zerguini, S., and Gaussier, N. 2017. "Modeling Households and firms location choice using agent-based models : application to the urban area of Bordeaux". Winter Simulation Conference, December 3-6, Las Vegas, NV, USA.

Courbet, D. 2011. "L'expérimentation en sciences de l'information et de la communication". In Objectiver l'humain? Volume 2: Communication et expérimentation, edited by S. Leleu-Merviel, pp. 31-69. Paris, Hermès-Lavoisier. 
Diallo, S. Y., Wildman, W. J., and Shults, F. L. 2019. "Human Simulation: A Transdisciplinary Approach to Studying Societal Problems". In Human Simulation: Perspectives, Insights, and Applications, edited by S. Y. Diallo, W. J. Wildman, F. L. Shults, and A. Tolk. Springer.

Johnson, R. B., and Onwuegbuzie, A. J. 2004. "Mixed Methods Research: A Research Paradigm Whose Time Has Come". Educational Researcher, vol. 33, pp. 14-26.

Maurel, M.-C. 2016. "Les sciences humaines et sociales : un paysage en recomposition”. In 1970-2010 Les sciences de l'Homme en débat, edited by Y. Brailowsky and H. Inglebert. Presses universitaires de Paris Nanterre.

Morillon, L. 2008. "Recueil et analyse des données en sciences humaines et sociales : un panorama". In Objectiver l'humain. Volume 1: qualification, quantification, edited by S. Leleu-Merviel, pp. 31-65. Paris, Hermès-Lavoisier.

Sbayou, M., Bouanan, Y., Zacharewicz, G., and Vallespir, B. 2019. "BPMN coordination and DEVS network architecture for healthcare organizations". In International Journal of Privacy and Health Information Management, IGI Global, vol. 7 (1), pp.103-115.

SNRI. 2010. Nouvelle nomenclature des Sciences de l'Homme et de la Société. Stratégie Nationale de Recherche et d'Innovation, Ministère de l'Enseignement Supérieur et de la Recherche.

Varenne, F. 2010. "Les simulations computationnelles dans les sciences sociales". Nouvelles perspectives en sciences sociales, vol. 5 (2), pp. 17-49.

Venkatesh, V., Brown, S. and Bala, H. 2013. "Bridging the qualitative-quantitative divide: Guidelines for conducting mixed methods research in information systems". MIS Quarterly, vol. 37 (1), pp. 21-54.

Zeigler, B. P., Traore M. K., Zacharewicz G., and Duboz R. 2019. Value-based learning healthcare systems. London, The Institution of Engineering and Technology.

Zerguini, S., Bouanan, Y., and Gaussier, N. 2017. "Agent-based modeling of urban land-use development: Simulating Housholds and firms location choice in Bordeaux. The XIV International Multidisciplinary \& Simulation Multi-Conference, September 18-20, Barcelona, Spain.

\section{AUTHOR BIOGRAPHIES}

NATHALIE PINEDE is an Associate Professor of Information and Communication Studies at Bordeaux Montaigne University. Her research interests lie in digital methods, communication strategy and uses of digital tools, including accessibility. Her email address is nathalie.pinede@u-bordeaux-montaigne.fr.

BRUNO VALLESPIR is a Full Professor at the university of Bordeaux and researcher at IMS laboratory. His research interests include industrial engineering, enterprise modelling and engineering, performance management and is currently involved in launching a major research project at the university of Bordeaux on the industry of the future. His email address is bruno.vallespir@ims-bordeaux.fr.

MAMADOU KABA TRAORÉ is a Full Professor at the university of Bordeaux and researcher at IMS laboratory. His research interests include model-based systems engineering, hybrid simulation, multiperspectives modelling. His email address is mamadou-kaba.traore@ims-bordeaux.fr.

SAIKOU Y. DIALLO is a Research Associate Professor at the Virginia Modeling, Analysis \& Simulation Center of the Old Dominion university. His research focuses on the theory of interoperability as it relates to model-based data engineering and web services for M\&S applications. His email address is SDiallo@odu.edu.

GREGORY ZACHAREWICZ is a Full Professor at IMT - Mines Ales (PRISM Department) and researcher at LGI2P laboratory. His research interests include enterprise modelling and interoperability, distributed simulation, synchronization algorithms, HLA, workflow, DEVS, multi-agents simulation, semantic approaches, ontology, ERP, BPMN. His email address is Gregory.Zacharewicz@mines-ales.fr. 